\title{
Behavior of oxygen doped SiC thin films: An x-ray photoelectron spectroscopy study
}

\author{
A. Avila and I. Montero a) \\ Instituto de Ciencia de Materiales de Madrid (CSIC), Cantoblanco 28049-Madrid, Spain \\ L. Galán and J. M. Ripalda \\ Departamento de Física Aplicada, Universidad Autónoma de Madrid, Cantoblanco 28049-Madrid, Spain \\ R. Levy \\ Department of Physics. New Jersey Institute of Technology, University Heights, Newark, New Jersey 07102
}

(Received 15 July 1999; accepted for publication 20 October 2000)

Thin silicon carbide films have been deposited by chemical vapor deposition on $p$-type (100) silicon substrates. The composition and bonds formed in these films have been analyzed by $\mathrm{x}$-ray photoelectron spectroscopy (XPS) and infrared spectroscopy. The native surface oxide on the silicon carbide surface induced by air exposure has also been studied. Several phases are detected in the near-surface region: elemental $\mathrm{Si}, \mathrm{Si}$ oxides (mainly $\left.\mathrm{SiO}_{2}\right)$, $\mathrm{Si}$ carbide $(\mathrm{SiC})$ and $\mathrm{Si}$ oxicarbides $\left(\mathrm{SiO}_{x} \mathrm{C}_{y}\right)$. Quantitative XPS analysis results indicate that, for atomic oxygen fractions $<0.15$, the $\mathrm{Si}-\mathrm{C}$ phases are dominant in the films. Above this value no silicon oxicarbide is observed, but a multiphase material formed by elemental $\mathrm{Si}$, Si oxides and Si carbides is observed. In spite of the film being a complex phase mixture, a simple relationship is found between the overall carbon and oxygen compositions. The carbon atomic fraction in the film decreases quasilinearly as the oxygen content increases, with a slope of about -1 . An overall composition of $\mathrm{SiO}_{x} \mathrm{C}_{3-x}$ in the $0.5<x$ $<2$ range is found for the phase mixture. A comparison with silicon carbide obtained by $\mathrm{CH}_{n}^{+}$ion implantation into monocrystalline silicon is made. (c) 2001 American Institute of Physics.

[DOI: $10.1063 / 1.1332796]$

\section{INTRODUCTION}

Silicon carbide is an important material for the manufacture of optic and electronic devices working at high temperature, high frequencies and high power. This is due to the outstanding properties of $\mathrm{SiC}$ films: wide band gap, high electric field breakdown, large value of thermal conductivity, and excellent chemical, mechanical and thermal stabilities. ${ }^{1-6}$ Silicon carbide exists in a large number of politypes or structural forms, with different stacking sequences of close-packed Si and C layers. ${ }^{7-9}$ Intense research has also been carried out on amorphous hydrogenated silicon carbide $(a-\mathrm{SiC}: \mathrm{H})$ because of its potential industrial applications. Moreover, silicon carbide can be oxidized to produce a stable and electrically insulating silicon dioxide passivating layer. ${ }^{10-18}$

Generally, silicon carbide films are prepared by several techniques such as chemical vapor deposition (CVD), sputtering, glow-discharge deposition, etc. ${ }^{19-22}$ In this work thin silicon carbide films were produced by CVD. An alternative route is the low-energy ion implantation of $\mathrm{CH}_{n}^{+}$ions into silicon. Low-energy ion implantation and ion-assisted growth processes, due to chemical reactions between the active ions and the substrate atoms, ${ }^{23-26}$ are a common trend in material technology. In this work, $\mathrm{x}$-ray photoelectron spectroscopy (XPS) and infrared spectroscopy (IR) have been used to study the differences in the atomic composition and

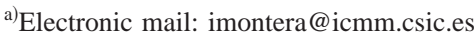

chemical bonding of $\mathrm{SiC}$ obtained by CVD and low-energy ion implantation of $\mathrm{CH}_{n}^{+}$ions into silicon. In addition, chemically inhomogeneous CVD $\mathrm{SiC}$ has also been studied. The chemical modifications due to oxidation of the SiC films in the near-surface region, induced by exposure to the air, are described. The influence of the oxygen concentration is also studied.

\section{EXPERIMENT}

Thin silicon carbide films were obtained by the CVD technique; $p$-type (100) silicon wafers polished on both sides were used as substrates, previously cleaned and degreased by the usual procedures. The reactor consisted of a conventional quartz tube heated in a furnace. Dichlorosilane and acetylene were used as precursor gases. During all depositions the pressure and temperature in the reactor were 200 mTorr and $1000^{\circ} \mathrm{C}$, respectively. The gas flow rates were kept at a constant value of either 10 or $50 \mathrm{sccm}$ (standard cubic centimeters per minute). The thickness of the CVD films was in the $0.05-1 \mu \mathrm{m}$ range as measured by a profilometer (Dektak 3030). The surface of the as-deposited $\mathrm{SiC}$ films was homogeneous without cracks but with a few voids, as shown by scanning electron microscopy analysis. ${ }^{19}$ In order to obtain chemically inhomogeneous $\mathrm{SiC}$ films (with unreacted $\mathrm{Si}$ and $\mathrm{C})$, the reactor geometry and the position of the wafers in the system are the most determinant parameters. Silicon carbide films were also synthesized by $\mathrm{CH}_{n}^{+}$ion-beam bombardment of $p$-Si at $2 \mathrm{keV}$. From calculated ion ranges the estimated carburized depth was $5 \mathrm{~nm}$. The ion bombardment was per- 


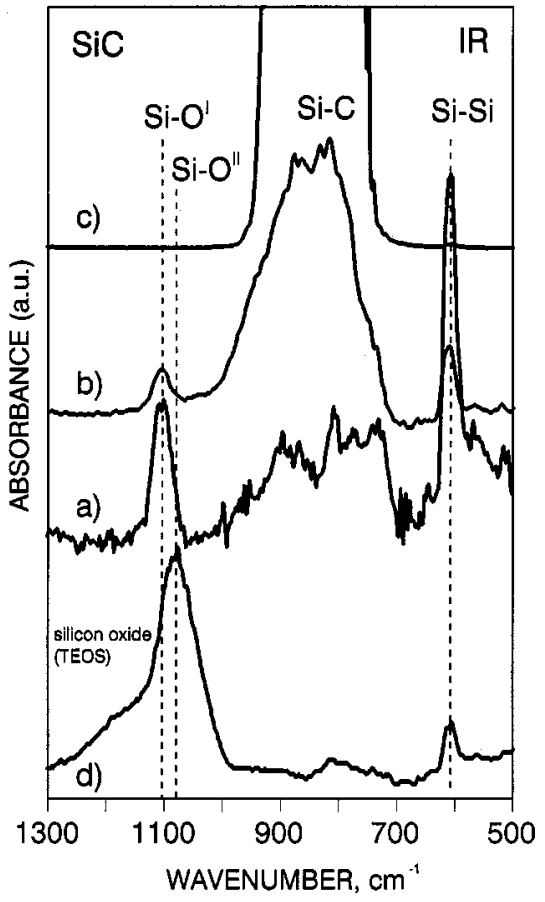

FIG. 1. IR spectra of CVD SiC of different thicknesses. The position of the $\mathrm{Si}-\mathrm{C}, \mathrm{Si}-\mathrm{O}^{I}, \mathrm{Si}-\mathrm{O}^{I I}$ and $\mathrm{Si}-\mathrm{Si}$ bands is marked. The TEOS silicon oxide has been included for comparison.

formed in an ultrahigh vacuum preparation chamber directly attached to the XPS analysis chamber. The ion source of the cold-cathode Penning type produced a $\mathrm{CH}_{n}^{+}$ion flux with mass not selected, ${ }^{27,28}$ of $20 \mu \mathrm{A}$ on a surface area of $1.5 \mathrm{~cm}^{2}$ $\left(\sim 8 \times 10^{13}\right.$ ions $\left./ \mathrm{cm}^{2} \mathrm{~s}\right) . \mathrm{CH}_{3}^{+}$is the most dominant ion in this type of plasma ion source.

XPS analysis was performed with a VGS ESCALAB 210 instrument using non-monochromatic $\mathrm{Mg} K \alpha(\mathrm{x}-$ radiation $(h \nu=1253.6 \mathrm{eV})$. The analyzer was operated in the constant-pass energy mode, the pass energies were 20 and 50 $\mathrm{eV}$ for the core level and survey spectra, respectively. The corresponding resolutions of the electron energy analyzer were $\sim 0.4$ and $\sim 1.0 \mathrm{eV}$, respectively ( $\sim 2 \%$ of pass energy). CVD SiC samples and $\mathrm{SiC}$ samples obtained by ion bombardment were analyzed ex situ and in situ, respectively. IR spectra were recorded ex situ in the transmission mode at normal incidence, in the $4000-250 \mathrm{~cm}^{-1}$ wave number range, using a double beam dispersive spectrophotometer (Hitachi mod. 270-5).

\section{RESULTS AND DISCUSSION}

Figure 1 shows the infrared spectra of thin silicon carbide films of different thickness, 0.05, 0.1 and $1 \mu \mathrm{m}$, spectra $a, b$, and $c$, respectively, obtained by CVD at $50 \mathrm{sccm}$. The spectrum of a tetraethylorthosilicate (TEOS) silicon oxide film, deposited at $700^{\circ} \mathrm{C}$ by decomposing tetraethoxysilane, $\mathrm{Si}\left(\mathrm{OC}_{2} \mathrm{H}_{5}\right)_{4}$, in a low-pressure CVD reactor, has been included for comparison (spectrum $d$ ) ${ }^{29}$ The presence of the strong peak at about $800 \mathrm{~cm}^{-1}$ is associated with the fundamental transversal optical phonon frequency of the $\mathrm{Si}-\mathrm{C}$ stretching vibration, labeled $\mathrm{Si}-\mathrm{C}$. The full width at half maximum (FWHM) of the $\mathrm{Si}-\mathrm{C}$ absorption band is $\sim 175$

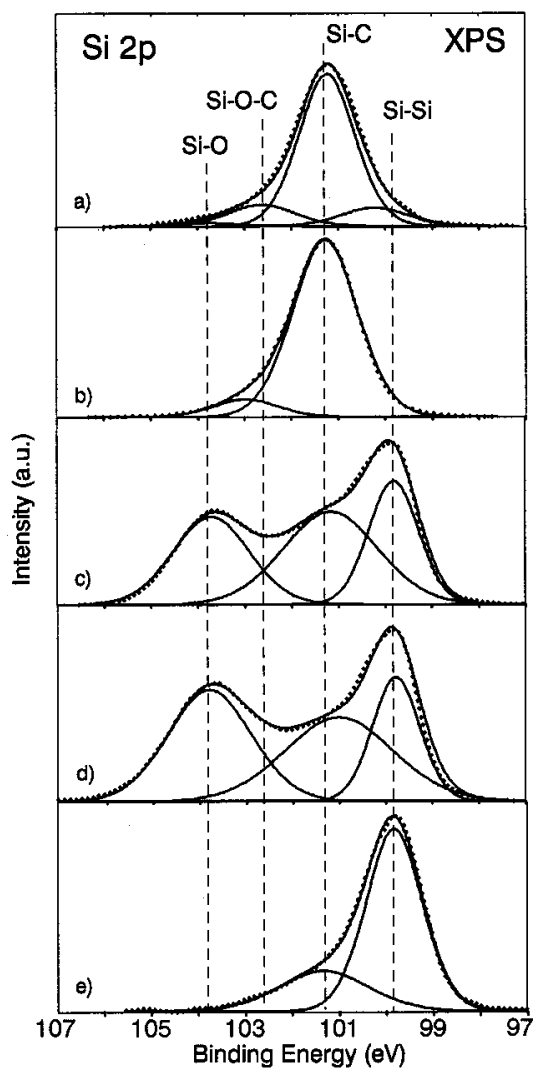

FIG. 2. Typical Si 2p core level XPS spectra of CVD silicon carbide, panels (a)-(d), and SIC obtained by $\mathrm{CH}_{n}^{+}$ion bombardment on $\mathrm{Si}$, panel e. The continuous lines show the results of computer-assisted peak separations into: $\mathrm{Si}-\mathrm{Si}, \mathrm{Si}-\mathrm{C}, \mathrm{Si}-\mathrm{O}-\mathrm{C}$ and $\mathrm{Si}-\mathrm{O}$ components of Gaussian/Lorentzian line shape and the resulting sum.

$\mathrm{cm}^{-1}$. This large value of FWHM can be attributed to the different $\mathrm{Si}-\mathrm{C}$ bond lengths and bond angles in an amorphous material. The absorption band located at $1100 \mathrm{~cm}^{-1}$, labeled $\mathrm{Si}-\mathrm{O}^{I}$, assigned to the $\mathrm{Si}-\mathrm{O}$ stretching vibration, is not associated with the presence of silicon oxide, and is attributed to interstitial oxygen impurities dissolved in the silicon substrate. For comparison, the absorption band located at $1070 \mathrm{~cm}^{-1}$ (spectrum $d$ ), labeled $\mathrm{Si}-\mathrm{O}^{I I}$, corresponds to the $\mathrm{Si}-\mathrm{O}$ bonds of the silicon oxide coating (TEOS). ${ }^{29}$ The narrow band observed in all spectra at about $600 \mathrm{~cm}^{-1}$ originates from the network vibration of the silicon substrate, labeled $\mathrm{Si}-\mathrm{Si}$. The intensities of both $\mathrm{Si}-\mathrm{Si}$ and $\mathrm{Si}-\mathrm{O}^{I}$ bands decreases with increasing thickness of the silicon carbide coating. The absence in the survey spectra of the CVD silicon carbide of the absorption bands due to the $\mathrm{Si}-\mathrm{H}$ and $\mathrm{C}-\mathrm{H}$ bonds, at $\sim 2100$ and $2900 \mathrm{~cm}^{-1}$, respectively, ${ }^{30}$ is worth noting.

The near-surface region of the silicon carbide was analyzed by XPS. Figure 2 shows the Si $2 p$ core level XPS spectra representative of silicon carbide films obtained by CVD at 10 and $50 \mathrm{sccm}$, panels (a) and (b), respectively. Surface regions with chemically inhomogeneous $\mathrm{SiC}$ formation, typical of inhomogeneous films, are shown in panels (c) and (d), respectively. The spectrum of silicon carbide obtained by ion implantation is also included for comparison, panel (e). The inelastic background of the XPS spectra was 
removed taking into account both secondary electrons and energy losses. ${ }^{31,32}$ The spectra are not normalized but for comparison a similar spectra intensity has been drawn. Si $2 p$ XPS spectra were resolved as sums of several components assuming that each peak has a Gaussian/Lorentzian line shape. Four main components were observed in the Si $2 p$ spectra: $\mathrm{Si}-\mathrm{Si}$ (elemental silicon) due to unreacted silicon or to the silicon substrate, $\mathrm{Si}-\mathrm{C}$ (silicon carbide), $\mathrm{Si}-\mathrm{O}-\mathrm{C}$ (silicon oxicarbide) and $\mathrm{Si}-\mathrm{O}$ (silicon oxide) located at 99.8 , 101.2, 102.7 and $103.8 \mathrm{eV}$ binding energies, respectively. ${ }^{33}$ These values are in good agreement with the values for pure stoichiometric phases: $\mathrm{Si}, \mathrm{SiC}, \mathrm{SiO}_{2}$, and also with those of oxicarbides found in the oxidation of $\mathrm{SiC}^{34}$ taking into account an offset of $-1 \mathrm{eV}$ to these values. ${ }^{35}$

The SiC CVD samples [panels (a) and (b)] in Fig. 2 show essentially one peak due to $\mathrm{SiC}$ formation. The small signals at higher and lower binding energies are associated with silicon oxicarbide and unreacted silicon contributions, respectively. Binding energies of Si $2 p$ levels in tetrahedrally coordinated compounds are mainly determined by nearest neighbor bonding and one can expect a nearly linear dependence with composition for saturated valence $\mathrm{SiO}_{x} \mathrm{C}_{y}$ compounds (if neither subcarbides nor suboxides are present). ${ }^{36,37}$ The binding energy of the silicon oxicarbide species $(102.6 \mathrm{eV})$ would correspond to a $\mathrm{SiO}_{1.2} \mathrm{C}_{0.4}$ phase if saturate valence is assumed (no $\mathrm{Si}-\mathrm{Si}$ bonds) and $\mathrm{C}-\mathrm{C}, \mathrm{C}-\mathrm{O}$ or $\mathrm{O}-\mathrm{O}$ bonds are not present. Similar compositions have been found for silicon oxicarbides formed by carbon incorporation in $\mathrm{SiO}_{2} \cdot{ }^{38}$ The spectral line attributed to silicon oxicarbide decreases and that of the unreacted silicon disappears with increasing gas flow during deposition. In the case of the inhomogeneous silicon carbide, apart from the $\mathrm{Si}-\mathrm{C}$ signal, $\mathrm{Si}-\mathrm{O}$ and $\mathrm{Si}-\mathrm{Si}$ signals are also detected (spectra $c$ and $d$ ). The signal of the elemental Si $2 p$ cannot correspond to the silicon substrate because the samples are much thicker than the XPS probing depth. This peak, however, is associated with the presence of unreacted silicon or hydrogenated silicon in the deposited film. Thus, it could happen that not all $\mathrm{Si}-\mathrm{H}$ bonds are replaced by $\mathrm{Si}-\mathrm{C}$ during growth and the coating would, therefore, become nonstoichiometric. $\mathrm{SiO}_{2}$ is formed but some kind of oxicarbide could also be present. The large widths of the peaks observed could be explained by the high chemical inhomogeneity. It is probable that, as well as tetrahedrally bonded $\mathrm{Si}\left(\mathrm{Si}_{-}-\mathrm{Si}_{4}, ..\right)$, corresponding to the stoichiometric phases, other phases are present (such as $\mathrm{Si}-\left(\mathrm{Si}_{l} \mathrm{C}_{m} \mathrm{O}_{n}\right),(l+m+n=4)$, corresponding to intermediate compounds. The line shape shown by the spectra, that can be fitted by a few peaks, means that the chemical contributions are not equally probable and tend to favor stoichiometric stable phases: $\mathrm{Si}, \mathrm{SiC}$ and $\mathrm{SiO}_{2}$.

Our results indicate that not all compositions $\left(\mathrm{SiO}_{x} \mathrm{C}_{1-x / 2}\right)$ are found but only those around the $\mathrm{Si}, \mathrm{SiC}$, $\mathrm{SiO}_{2}$ and $\mathrm{SiO}_{1.2} \mathrm{C}_{0.4}$ values. The composition $\mathrm{SiO}_{1.2} \mathrm{C}_{0.4}$ $\left(\mathrm{SiO}_{x} \mathrm{C}_{1-x / 2}, x=1.2\right)$ is evaluated in terms of the centroid of the Si $2 p$ core level spectrum. The method is based on the basic principle of electron spectroscopy for chemical analysis, i.e., the additive property of the chemical shifts and their proportionality to ligand coordination. ${ }^{39}$ The large values found for the widths of the corresponding spectral contribu-

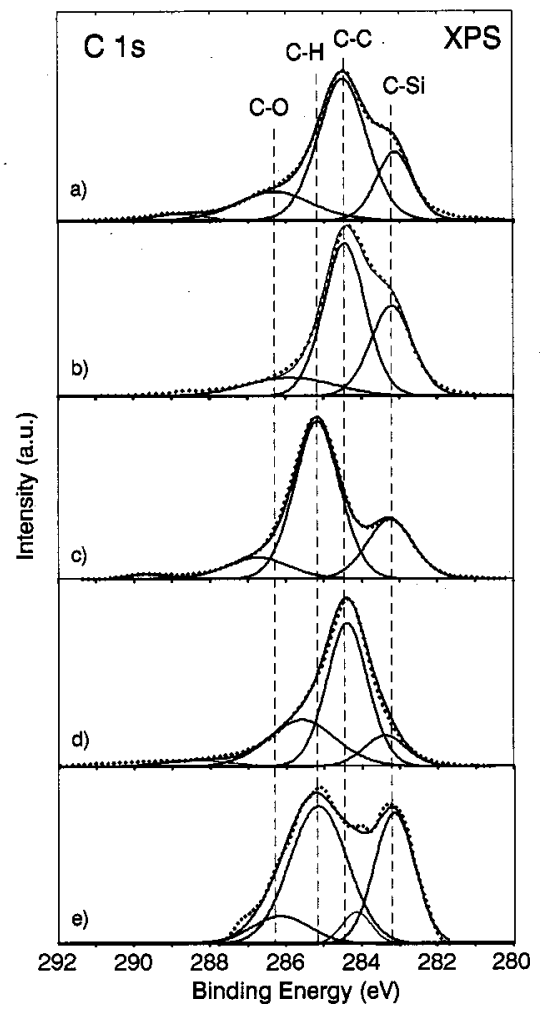

FIG. 3. C 1s core level spectra of the same samples of Fig. 2. The continuous lines show the mathematical fit with $\mathrm{C}-\mathrm{O}, \mathrm{C}-\mathrm{H}, \mathrm{C}-\mathrm{C}$ and $\mathrm{C}-\mathrm{Si}$. components and the resulting sum.

tions, with a 2.0-2.5 eV FWHM, indicate the existence of amorphous disordered phases and incomplete phase separation. The silicon carbide obtained by low-energy $\mathrm{CH}_{n}^{+}$ion implantation shows two contributions assigned to $\mathrm{SiC}$ and $\mathrm{Si}$ substrate signals, panel (e) in Fig. 2. We can observe that the positions of these peaks coincide with those of the CVD SiC films.

A spectral series of $\mathrm{C} 1 s$ core level peaks of the same samples as Fig. 1 is shown in Fig. 3 [panels (a)-(e)]. Four main contributions can be identified due to: $\mathrm{C}-\mathrm{Si}$ (carbon in $\mathrm{Si}$ carbide and Si oxicarbide), $\mathrm{C}-\mathrm{C}$ (carbon in $a-\mathrm{C}$ or graphite), $\mathrm{C}-\mathrm{H}$ (carbon in $a-\mathrm{C}: \mathrm{H}$ or carbon bonded to $\mathrm{H}$ ) and $\mathrm{C}-\mathrm{O}$ (carbon bonded to $\mathrm{O}, \mathrm{C}-\mathrm{O}$ or $\mathrm{C}=\mathrm{O}$, in above phases), at 283.2, 284.4, 285.1 and $286-287 \mathrm{eV}$ binding energies, respectively. In the CVD $\mathrm{SiC}$ spectra, the $\mathrm{C}-\mathrm{Si}, \mathrm{C}-\mathrm{C}$ and $\mathrm{C}-\mathrm{O}$ signals in $\mathrm{C} 1 s$ are present [panels (a) and (b)]. ${ }^{33} \mathrm{We}$ can observe that the $\mathrm{SiC}$ contribution increases with increasing gas flux (sccm value) during deposition. Simultaneously, the $\mathrm{C}-\mathrm{O}$ oxide signal is more intense in the samples obtained at lower fluxes $(10 \mathrm{sccm})$. The intensity of the oxicarbide signal in the $\mathrm{C} 1 s$ peak is expected to be very weak and completely masked by the $\mathrm{C}-\mathrm{C}, \mathrm{C}-\mathrm{H}$ and $\mathrm{C}-\mathrm{Si}$ signals and it is, therefore, very difficult to determine univocally its intensity by mathematical fits. It is more difficult to detect $\mathrm{Si}-\mathrm{C}-\mathrm{O}$ in the $\mathrm{C} 1 s$ peak than in the $\mathrm{Si} 2 p$ one because of the additional strong $\mathrm{C}-\mathrm{C}$ and $\mathrm{C}-\mathrm{H}$ signals. Both Figs. 3(c) and 3(d) correspond to inhomogeneous CVD SiC. These two chemically inhomogeneous $\mathrm{SiC}$ samples were obtained under the same preparation conditions, but their positions in the CVD system were not identical. The two samples are similar with respect 


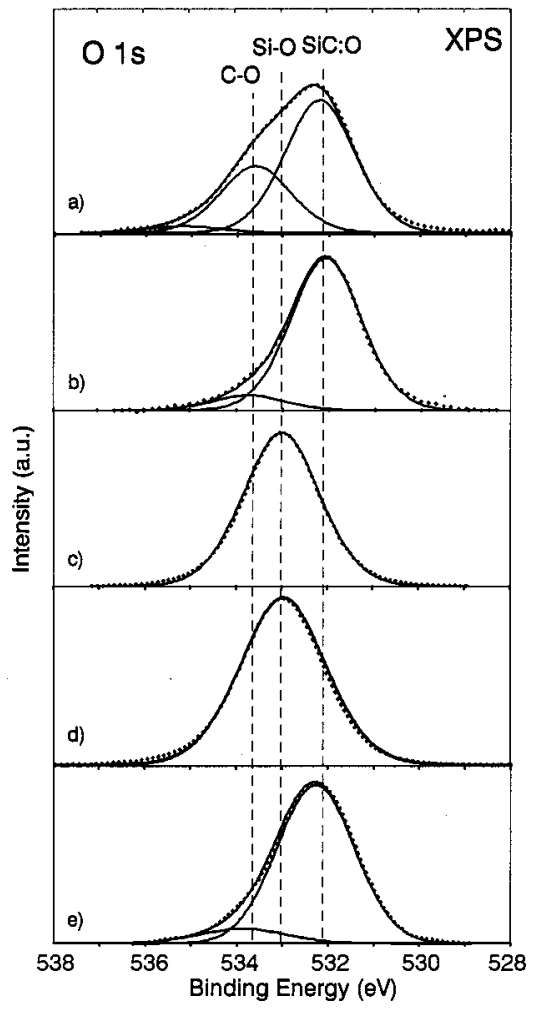

FIG. 4. O 1s core level spectra of the same samples of Fig. 2. The continuous lines show the mathematical fit with $\mathrm{C}-\mathrm{O}, \mathrm{Si}-\mathrm{O}$ and $\mathrm{SiC}: \mathrm{O}$ components and the resulting sum.

to the silicon-containing phases, but not with respect to unreacted carbon since they have different concentrations of $\mathrm{C}-\mathrm{C}$ and $\mathrm{C}-\mathrm{H}$ bonds. These samples are both a phase mixture but they are not identical. In ion implanted $\mathrm{SiC}$, panel (e), the $\mathrm{C} 1 s$ signal contains two main peaks, associated with $\mathrm{SiC}$ and amorphous hydrogenated carbon. The two small peaks, labeled $\mathrm{C}-\mathrm{C}$ and $\mathrm{C}-\mathrm{O}$, also correspond to carbon atoms in amorphous hydrogenated carbon. Thus, in the amorphous hydrogenated carbon, some atoms are only bonded to other $\mathrm{C}$ atoms and appear as a small signal at $284.2 \mathrm{eV}$, whereas others are oxidized at $286.2 \mathrm{eV}$. The presence of carbon atoms not included in bonds with silicon (C-O, $\mathrm{C}-\mathrm{C}$ and $\mathrm{C}-\mathrm{H}$ bonds) has not been detected by $\mathrm{IR}$ in the deposited coatings. This could be principally explained by the combined use of surface and bulk sensitive techniques (XPS and IR, respectively). The XPS technique only allows the identification of elements and chemical states present in the outermost $(\sim 5 \mathrm{~nm})$ region of the samples, close to the surface. The surface layer of $2 \mathrm{~nm}$ causing the main signal in XPS $(70 \%)$ can practically not be detected by IR in samples with a total thickness of $\sim 1 \mu \mathrm{m}$.

Figure 4 shows the corresponding O $1 s$ core level spectra of the same samples of Figs. 2 and 3. Three components, associated with $\mathrm{Si}-\mathrm{C}: \mathrm{O}$ (oxygen in silicon oxicarbide) at $532.2 \mathrm{eV}, \mathrm{O}-\mathrm{Si}$ (oxygen in silicon oxide) at $533.0 \mathrm{eV}$ and $\mathrm{O}-\mathrm{C}$ (oxygen bonded to carbon) at $533.6 \mathrm{eV}$, were used for the mathematical fits. ${ }^{33}$ The $533.6 \mathrm{eV}$ peak can be attributable to oxygen bonded to carbon $(\mathrm{C}-\mathrm{O}) .{ }^{40}$ The $\mathrm{O} 1 s$ spectra of the CVD $\mathrm{SiC}$ films show principally the $\mathrm{Si}-\mathrm{O}-\mathrm{C}$ or $\mathrm{SiC}: \mathrm{O}$ contribution and a small signal due to $\mathrm{O}$ bonded to $\mathrm{C}$.

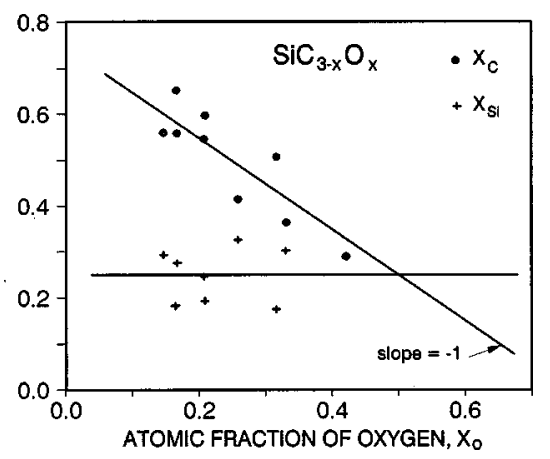

FIG. 5. Relationship between the silicon and carbon atomic fractions, $x_{\mathrm{Si}}$, $x_{\mathrm{C}}$, respectively, and the oxygen atomic fraction, $x_{\mathrm{O}}$.

On the other hand, the spectra of the inhomogeneous silicon carbide films are dominated by the $\mathrm{SiO}_{2}$ signal. The $\mathrm{O} 1 \mathrm{~s}$ line in Figs. 4(c) and 4(d) has been fitted using only a symmetrical peak and has been attributed to $\mathrm{O}-\mathrm{Si}$ species. The $\mathrm{C}-\mathrm{O}$ contribution is detected in the corresponding $\mathrm{C} 1 s$ line. However, the amount of the corresponding $\mathrm{O}$ is much smaller than the amount of $\mathrm{O}$ bonded to $\mathrm{Si}$. The $\mathrm{O} 1 s$ peak of spectrum e (Fig. 4) has a small intensity and is principally attributed to the oxygen dissolved in the $\mathrm{SiC}$ network. Also, a small peak associated with $\mathrm{C}-\mathrm{O}$ is observed. For this reason, the $\mathrm{Si}-\mathrm{O}$ and $\mathrm{Si}-\mathrm{O}-\mathrm{C}$ species are not detected in the corresponding Si $2 p$ line.

The main effect of air exposure on the near-surface region of $\mathrm{SiC}$ obtained by CVD can be adequately described by the resulting oxygen concentration. The average nearsurface composition has been calculated from the atomic fractions $x_{\mathrm{Si}}, x_{\mathrm{C}}$ and $x_{\mathrm{O}}$, where $x_{\mathrm{Si}}=I_{\mathrm{Si}} /\left(I_{\mathrm{Si}}+I_{\mathrm{C}}+I_{\mathrm{O}}\right), x_{\mathrm{C}}$ $=I_{\mathrm{C}} /\left(I_{\mathrm{Si}}+I_{\mathrm{C}}+I_{\mathrm{O}}\right)$ and $x_{\mathrm{O}}=I_{\mathrm{O}} /\left(I_{\mathrm{Si}}+I_{\mathrm{C}}+I_{\mathrm{O}}\right) . I_{\mathrm{Si}}, I_{\mathrm{C}}$ and $I_{\mathrm{O}}$ are the XPS integrated intensities for Si $2 p, \mathrm{C} 1 s$ and $\mathrm{O} 1 s$ corrected by the corresponding XPS sensitivity factors: 0.24 , 0.27 and 0.71 , respectively. ${ }^{41}$ The overall surface composition $\mathrm{SiO}_{x} \mathrm{C}_{3-x}$ for $0.5<x<2$ is obtained, while for a saturated oxicarbide (no $\mathrm{C}-\mathrm{O}$ bonds) $\mathrm{SiO}_{x} \mathrm{C}_{1-x / 2}$ would be expected, showing that the samples have an excess of nonbonded (unreacted) carbon and that $\mathrm{C}-\mathrm{O}$ bonds are formed, as Figs. 3 and 4 show. The dependences of the carbon and silicon atomic fractions, $x_{\mathrm{C}}$ and $x_{\mathrm{Si}}$, versus the oxygen atomic fraction, $x_{\mathrm{O}}$, are plotted in Fig. 5. We can observe only one trend: the concentration of carbon in the film decreases quasilinearly as the oxygen concentration increases, with a slope $\sim-1$. In addition, $x_{\mathrm{Si}}$ is practically independent of $x_{\mathrm{O}}$. The formation of $\mathrm{SiO}_{2}, \mathrm{CO}$ and $\mathrm{CO}_{2}$ during the oxidation process of the $\mathrm{SiC}$ has been well established]. ${ }^{42,43}$ Due to their larger size, a residue of $\mathrm{CO}_{2}$ molecules could remain in the sample if there is no channel through which they can go from the void to the outside. It is necessary to deform the network to allow $\mathrm{CO}_{2}$ molecules to diffuse in the material. It can be observed that the samples with higher $\mathrm{C}$ content are less oxidized and those with carbon atoms not included in bonds with silicon (higher elemental silicon content) are the most oxidized. This probably happens because the carburization process of silicon partially inhibits oxidation. 


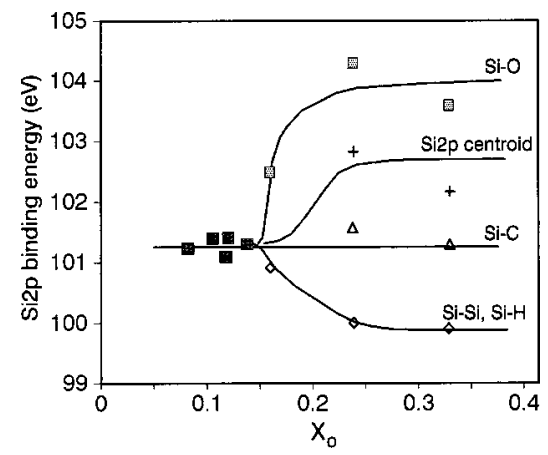

FIG. 6. Positions of the Si $2 p$ centroid and of the components of Si $2 p$ line as a function of the oxygen atomic fraction.

Figure 6 presents the centroid position of the total line shape and the three main components of the Si $2 p$ core level spectra (see Fig. 2) as a function of $x_{\mathrm{O}}$. For clarity, only the positions of the spectral lines with relative intensities $>10 \%$ have been shown. We can observe that for $x_{\mathrm{O}}<0.15$ the principal contribution is due to the $\mathrm{SiC}$ signal. The observed oxygen cannot be explained by the negligible amount of oxidized species. It is probably dissolved oxygen in SiC. Surprisingly, for $x_{\mathrm{O}}>0.15$ a pronounced splitting of the Si $2 p$ signal is observed: $\mathrm{Si}-\mathrm{Si}, \mathrm{Si}-\mathrm{C}$ and $\mathrm{Si}-\mathrm{O}$ phases are present. In addition, the $\mathrm{Si} 2 p$ centroid shifts towards higher binding energies. The incorporation of most of the oxygen into the $\mathrm{SiC}$ thin films is thus not associated with the formation of silicon oxicarbide, in good agreement with a previous work. ${ }^{38}$ This could be explained by $\mathrm{SiC}$ being more resistant to oxidation than elemental $\mathrm{Si}$, so that samples with higher content of unreacted $\mathrm{Si}$ are more oxidized. These results suggest that the oxidation process is governed by the formation of $\mathrm{SiO}_{2}, \mathrm{CO}$ and $\mathrm{CO}_{2}$ and loss of the carbon atoms.

\section{SUMMARY AND CONCLUSIONS}

Silicon carbide coatings formed by CVD and deposited on monocrystalline silicon have been studied by XPS and IR techniques. Chemically inhomogeneous samples were also studied. In these materials, a broad range of Si chemical configurations are present, from that in elemental Si to that in $\mathrm{SiO}_{2}$, including $\mathrm{SiC}$ and intermediate nonstoichiometric compounds. A comparison with the $\mathrm{SiC}$ obtained by lowenergy $\mathrm{CH}_{n}^{+}$ion implantation into monocrystalline silicon has been made. We have reported a study of the evolution of the thin silicon carbide films after exposure to air. For oxygen atomic fractions $x_{\mathrm{O}}<0.15$ the deposited coating is mainly composed of $\mathrm{SiC}$, but for $x_{\mathrm{O}}>0.15$ a drastic splitting of the $\mathrm{Si} 2 p$ core level peak is observed. $\mathrm{SiC}, \mathrm{Si}, \mathrm{SiO}_{2}$ and $\mathrm{C}$ phases are then present in the films but only a negligible amount of silicon oxicarbide compound is formed. Also, the silicon atomic fraction remains nearly constant with increasing oxygen concentration. Surface oxidation proceeds by oxidation of the unreacted $\mathrm{Si}$ and by substitution of $\mathrm{C}$ by $\mathrm{O}$ leading probably to the desorption of $\mathrm{CO}$ and $\mathrm{CO}_{2}$.

\section{ACKNOWLEDGMENTS}

This work has been supported by the Comunidad de Madrid (Spain), Project No. 07N/0044/1998 and by the CICYT (Spain) Project No. ESP99-1112 and the Commission for Cultural and Scientific Exchange between the United States and Spain, Project No. 99105.

${ }^{1}$ H. Suzuki, Prog. Theor. Phys. 62, 936 (1979).

${ }^{2}$ J. Bullot and M. P. Schmidt, Phys. Status Solidi B 143, 345 (1987).

${ }^{3}$ W. Wesch, Nucl. Instrum. Methods Phys. Res. B 116, 305 (1996).

${ }^{4}$ G. Müller, G. Krötz, and N. Niemann, Sens. Actuators 43, 259 (1994).

${ }^{5}$ J. H. Edgar, J. Mater. Res. 7, 235 (1992).

${ }^{6}$ R. F. Davis and J. T. Glass, Advances in Solid-State Chem. 2, 1 (1991).

${ }^{7}$ G. R. Fisher and P. Barnes, Philos. Mag. B 61, 217 (1990).

${ }^{8}$ Z. F. Feng, A. Rohatgi, C. C. Tin, R. Hu, A. T. S. Wee, and K. P. Se, J. Electron. Mater. 25, 917 (1996).

${ }^{9}$ W. R. L. Lambrecht, B. Segall, W. Suttrop, M. Yoganathan, R. P. Devaty, W. J. Choyke, J. A. Edmond, J. A. Powell, and M. Alouani, Appl. Phys. Lett. 63, 2747 (1993).

${ }^{10}$ Z. Zheng, R. E. Tressler, and K. E. Spear, J. Electrochem. Soc. 137, 854 (1990).

${ }^{11}$ Ion beam assisted film growth. Beam modification of materials 3, edited by I. Itoh (Elsevier, Amsterdam, 1989).

${ }^{12}$ V. V. Afanas'ev, M. Bassler, G. Pensi, M. J. Schulz, and E. Stein von Kamienski, J. Appl. Phys. 79, 3108 (1996).

${ }^{13}$ A. Rys, N. Singh, and M. Cameron, J. Electrochem. Soc. 142, 1318 (1995)

${ }^{14}$ L. U. J. T. Ogbuji and E. J. Opila, J. Electrochem. Soc. 142, 925 (1995).

${ }^{15}$ D. M. Brown, M. Ghezzo, J. Kretchner, E. Downey, J. Pimbley, and J. Palmour, IEEE Trans. Electron Devices 41, 618 (1994).

${ }^{16}$ L. U. J. T. Ogbuji, J. Electrochem. Soc. 145, 2876 (1998).

${ }^{17}$ B. Schneider, A. Guette, and A. Costecalde, J. Mater. Sci. 33, 535 (1998).

${ }^{18}$ D. S. Fox, J. Am. Ceram. Soc. 81, 945 (1998).

${ }^{19}$ C. C. Chiu, S. B. Desu, and C. Yi Tsai, J. Mater. Res. 8, 2617 (1993).

${ }^{20}$ D. S. Kim and Y. H. Leo, J. Electrochem. Soc. 142, 3493 (1995).

${ }^{21}$ Y. Gao and J. H. Edgar, J. Electrochem. Soc. 144, 1875 (1997).

${ }^{22}$ S. Wickramanayaka, Y. Hatanaka, Y. Nakanishi, and A. M. Wrobel, J. Electrochem. Soc. 141, 2911 (1994).

${ }^{23}$ R. Trehan, Y. Lifshitz, and J. W. Rabalais, J. Vac. Sci. Technol. A 8, 4026 (1990).

${ }^{24}$ P. Mezentzeff, Y. Lifshitz, and J. W. Rabalais, Nucl. Instrum. Methods Phys. Res. B 44, 289 (1990).

${ }^{25}$ Y. Lifshitz, S. R. Kasi, and J. W. Rabalais, Phys. Rev. B 41, 10468 (1990)

${ }^{26}$ Y. Lifshitz, S. R. Kasi, and J. W. Rabalais, Phys. Rev. Lett. 62, 1290 (1989).

${ }^{27}$ H. Plank, W. Wang, W. Eckstein, R. Schwörer, H. J. Steffen, and J. Roth, J. Appl. Phys. 78, 5366 (1995).

${ }^{28}$ G. J. Vandentop, M. Kawasaki, R. M. Nix, I. G. Brown, M. Salmeron, and G. A. Somorjai, Phys. Rev. B 41, 3200 (1990).

${ }^{29}$ F. Fracassi, R. D’Agostino, and P. Favia, J. Electrochem. Soc. 139, 2636 (1992).

${ }^{30}$ K. Rottner and R. Helbing, Appl. Phys. A: Solids Surf. 59, 427 (1994).

${ }^{31}$ D. A. Shirley, Phys. Rev. B 5, 4740 (1972).

${ }^{32}$ H. E. Bishop, Surf. Interface Anal. 3, 272 (1981).

${ }^{33}$ NIST x-ray photoelectron spectroscopy database (1997). Gaitherburg, MD.

${ }^{34}$ F. J. Grunthaner and P. J. Grunthaner, Mater. Sci. Rep. 1, 65 (1986).

${ }^{35}$ C. Önneby and C. G. Pantano, J. Vac. Sci. Technol. A 15, 1597 (1997).

${ }^{36}$ R. C. Fang and L. Ley, Phys. Rev. B 40, 3818 (1989).

${ }^{37}$ R. Kärcher, L. Ley, and R. Johnson, Phys. Rev. B 30, 1896 (1984).

${ }^{38}$ I. Montero, L. Galán, F. Rueda, and J. Perrière, Surf. Sci. 298, 79 (1993).

${ }^{39}$ L. Galán, P. Prieto, C. Morant, L. Soriano, J. M. Sanz, E. Elizalde, and F. Rueda, Surf. Interface Anal. 19, 205 (1992).

${ }^{40}$ G. P. López, D. G. Castner, and B. D. Ratner, Surf. Interface Anal. 17, 267 (1991).

${ }^{41}$ C. D. Wagner, W. M. Riggs, L. E. Davis, and J. F. Moulder, Handbook of X-Ray, Photoelectron Spectroscopy, edited by G. E. Muilenberg (PerkinElmer, Eden Prairie, MN)

${ }^{42}$ R. W. Kee, K. M. Geib, C. W. Wilmen, and D. K. Ferry, J. Vac. Sci. Technol. 15, 1520 (1978).

${ }^{43}$ L. U. J. T. Ogbuji and E. J. Opila, J. Electrochem. Soc. 142, 925 (1995). 